\title{
NÃO FAZEM MAL AS MUSAS AOS... ALFAIATES*: UM PROFESSOR INTELECTUAL EM VITÓRIA DA CONQUISTA-BA - O CASO DE LAUDIONOR DE ANDRADE BRASIL
}

\author{
Daniela Moura Rocha de Souza** \\ Lívia Diana Rocha Magalhães ${ }^{* * *}$
}

\section{RESUMO}

Entre os finais do século XIX até meados da década de 40 do século XX, durante os primeiros anos da República no Brasil, compareceram, no cenário de Vitória da Conquista, cidade do interior da Bahia, alguns professores que passaram também a exercer o cargo de jornalistas, participar ativamente das discussões políticas e a exercer cargos de secretários municipais, vereadores, conselheiros, membros de partidos, etc. Possivelmente, eles foram dando identidade intelectual à República em nossa cidade no estágio de seu contexto de instalação e efetivação. Dentre os nomes que se destacaram nesse período, em Vitória da Conquista estava a figura do professor, jornalista, político e poeta Laudionor de Andrade Brasil.

Palavras-chave: Professor intelectual; República; Vitória da Conquista.

\section{DO NOT EVIL TO THE MUSES ... TAILOR: A INTELLECTUAL TEACHER IN VITORIA DA CONQUISTA-BA - THE CASE OF THE LAUDIONOR ANDRADE BRASIL}

\begin{abstract}
Between the late nineteenth century until the mid-40th century XX, during the early years of the Republic in Brazil, attended, in the scenario of Vitória da Conquista, Bahia inner city, some teachers who now also hold the position of journalists, actively participate in political discussions and hold positions of municipal secretaries, councilors, councilors, party members, etc. Possibly, they were giving the Republic intellectual identity in our city at the stage of its installation and execution context. Among the names that stood out in this period, in Vitória da Conquista was the figure of the teacher, journalist, politician and poet Laudionor Andrade Brasil.

Keywords: Intellectual Teacher, Republic, Vitória da Conquista.
\end{abstract}

Durante a década de 1920 o Brasil experimentava uma efervescência ideológica, que se misturava aos ideais libertários republicanos. Além dos positivistas e liberais, que se imbricavam com os valores tradicionais, a influência anarquista dos trabalhadores das indústrias, trazida, sobretudo, pelos imigrantes italianos, faziam também parte desse cenário, incorporando aos ideais de igualdade e liberdade, o fim da exploração em prol de uma sociedade justa, foi assim que Carone (1978) inseriu, por exemplo, as ondas de greves da década de 1910, sobretudo, de influências anarcossindicalistas, através das organizações do operariado brasileiro e criação de sindicatos profissionais. Para Maram (1979), eles desejavam abolir o Estado ou qualquer tipo de associação que fomentasse na exploração do trabalho assalariado ou não. A imprensa que desde a instalação da República desempenhava papel importante, na defesa ou combate de ideais, a partir daí, juntamente com outros recursos como revistas e literatura, se tornou grande aliada nas lutas políticas, 
defendendo os grupos que estavam inseridos os proprietários e redatores dos jornais, tanto do lado da situação quanto da oposição (LEONARDI; HARDMAN, 1991).

Desse modo com o primeiro governo de Vargas (1930-1945), como ressalta Silva (2000), a posição de intelectual nesse período era almejada, tanto em âmbito nacional, quanto regional e local, porque implicava intervir diretamente com a comunidade, através da política e dos próprios meios de comunicação. Indicava status, e alguns professores, almejaram e ocuparam os espaços, que permitiam essa titulação, que começaria com a imprensa - o principal meio de divulgação de produção intelectual - além de abrir as portas para os cargos públicos e para o ingresso na política e compensava ainda que não financeiramente, pela projeção social que proporcionava. A iniciação ao jornalismo se dava a partir de indicações de amizade, simpatia, filiações políticas, etc, e era ocupada por professores, advogados, médicos, engenheiros, literatos. Além desse espaço,

[...] as salas de aula consistiam em locais cobiçados e importantes. Ser professor secundário possuía suas vantagens. Era um ensino destinado á elites. Assim como a imprensa, o ensino facilitava o acesso aos estratos dirigentes e mantinha atualizados os contatos entre os seus membros. [...] Havia ainda outros meios de manifestação da vida intelectual tão relevantes quanto a imprensa e as salas de aula: as conferências, os discursos, os recitais. Não é por acaso que a Bahia, por exemplo, adquiriu renome pelos seus oradores. Como já mencionado anteriormente, até mesmo artigos de jornais pareciam escritos para ser lidos em voz alta. (SILVA, 2000, p.88)

O professor que se dirigia diretamente ao público, por meio da sala de aula e por diversos meios de comunicação que lhe era franqueado, foi assim legitimando sua categoria, com a função de intelectual, o que o levou a ocupar muitas vezes outros espaços seja nos salões privados ou públicos. Através dos agrupamentos literários, nos grêmios, nas alas, etc, que proporcionavam revistas literárias, e mais respaldo social perante a população, expandindo ainda mais a condição do ser intelectual e político.

Todas as ideias que circulavam por todo o país, imbricando muitas vezes valores distintos, formavam uma realidade heterogênea desde a proclamação da República em 1889, daí alguns autores como Holanda (2007), Carvalho (1998), Oliveira (1975), considerarem que o processo de instalação e desenvolvimento do regime republicano no Brasil foi marcado por uma verdadeira confusão que estava presente em todos os setores inclusive na Educação. O que nos permite concluir que apesar do discurso republicano de identidade nacional, esta estava longe de ser realizada.

Laudionor de Andrade Brasil foi um homem fruto desse tempo e sua atuação decorre das transformações ocorridas em um dado período histórico, das experiências vividas e compartilhadas dentro dos grupos que pertencia, seja na família, no trabalho, na religião, nos ideais, etc. Mesmo, com as singularidades individuais ele não era um sujeito isolado da realidade que fazia parte, pois sua atuação era conectada aos acontecimentos e aos grupos nos quais ele estava inserido. É importante ressaltar que o exemplo de Laudionor Brasil, que se destacou, juntamente com outros professores, na cidade, como político e intelectual, atuando na sala de aula, nas agremiações literárias, na imprensa, e na política, não era uma particularidade local. Nos âmbitos regional e nacional, temos exemplos como, Olavo Bilac, Cecília Meirelles, Mário de Andrade, Carlos Chiaccio, dentre outros, que se destacaram, principalmente, na conjuntura dos anos de 1930 a 1950 como interlocutores do republicanismo que se efetivava.

A cidade de Vitória da Conquista, nesse contexto acima citado, ainda se encontrava marcada pela tradição de uma cultura política baseada na dominação, resultante do 
mandonismo local, que misturava os assuntos de família e políticos, proporcionando as elites locais, além dos meios de produção, o controle social e o destino político da população seja ela urbana ou rural, mesmo após o período de 1930, porém, já incorporava desde a década de 1920 outros elementos como: o crescimento dos profissionais liberais, do comércio, da urbanização, etc, que introduzia gradativamente novos personagens, oriundos de camadas mais abastadas e médias nos espaços da cidade, inclusive naqueles que outrora eram ocupados apenas pela camada dominante, como os jornais e as agremiações culturais. E foi nessa realidade que viveu e atuou o filho de um carpinteiro e aprendiz de alfaiate Laudionor de Andrade Brasil, o baiano de "gravata escandalosa"1.

\section{Laudionor de Andrade Brasil: Vinte anos de amor e de tortura ${ }^{2}$}

Nascido no dia 13 de fevereiro de 1901, em Vitória da Conquista, Laudionor de Andrade Brasil ${ }^{3}$, filho do carpinteiro Manoel de Sena Brasil e Henriqueta Andrade Brasil, iniciou seus estudos primários em 1907, se estendendo até 1910, na escola pública da professora Honorina Andrade concluindo até o terceiro ano primário. Desde criança que ele começara a trabalhar em casas comerciais da cidade, continuando como balconista até 1920. A partir desse período foi ser aprendiz de alfaiate na alfaiataria de Otávio Moreira, permaneceu até 1922, quando foi sorteado a prestar o serviço militar em Maceió. Cabe ressaltar que em 1918, ele já publicava poesias no Jornal a Palavra, cujos redatores eram os professores Ernesto Dantas Barbosa e Euclydes Abelardo de Souza Dantas. Em 1920 foi um dos fundadores do Grêmio Dramático Castro Alves que abrigava os considerados letrados e intelectuais da cidade, nesse espaço ocorriam recitais de poesias, apresentação de corais, teatros e filarmônicas e também discussões políticas que de acordo Lima (in: BRASIL, 2002, p. 17) se caracterizava por

um grupo de rapazes disputando um lugar ao sol; fazendo festas e discursos no grêmio Dramático Castro Alves, também tão tipicamente provinciano, com seus dramalhões de capa e espada, seus atores travesti de ingênuas baronesas; com suas arrancadas cívicas inconscientemente lutas contra a reação e o preconceito, arregimentado nas sus fileiras até elementos da classe dominante, que pela primeira vez, deixavam conduzir por comerciantes e artíficies.

Durante o período que prestou serviço militar, foi apelidado de Balico, por alguns companheiros seus do Batalhão de Caçadores, em Maceió, onde ele ficou até 1924, quando retornou para Vitória da Conquista e foi trabalhar em lojas comerciais. Foi a partir da década de $1920^{4}$, que Laudionor, tornou-se auxiliar de ensino e mais tarde Diretor do estabelecimento do professor Euclydes Dantas o Educandário Sertanejo, sendo que pouco tempo depois ele manteve sua própria escola. Em 1930 fundou o Externato Brasil ${ }^{5}$, colégio situado ao lado da tipografia do Combate ${ }^{6}$, jornal fundado pelo mesmo em 1929.

Laudionor Brasil, não era adepto do Partido Comunista criado e liderado por Luiz Carlos Prestes em 1920, não defendia uma revolução socialista, porém defendia o fim da exploração dos menos favorecidos e uma sociedade igualitária e justa, as lutas populares e uma sociedade aos moldes da fraternidade cristã, como católico fervoroso que era através do caminho da educação. Suas contradições faziam com que respeitasse a ordem, propagasse o progresso, defendesse a educação moderna, repugnasse toda forma ditatorial, e de opressão, bem como a riqueza proveniente das elites que monopolizassem o poder, embora defendesse veementemente Getúlio Vargas, as ideias liberais e ascendesse socialmente adquirindo prestígio social da cidade. 
Foi essa figura contraditória que juntamente com outras pessoas fundou o Partido Liberal Conquistense ao lado do grande fazendeiro batista Cel. Deraldo Mendes, apoiando a candidatura de Vargas em 1930, a fim de concitar a população a votar em Getúlio. Ele redigiu o Manifesto do Partido Liberal, apoiando a revolução de 1930, da mesma forma que publicou um livro de crônicas e poesias intitulado: De lenço vermelho: crônicas em defesa da aliança liberal em coautoria com o jornalista Bruno Bacelar de Oliveira. Sousa e Borborema (2001) enfatizam que a atuação desses intelectuais não se restringia apenas a exaltação do partido liberal, de seus líderes, seus discursos, etc. Através das coletâneas de artigos, principalmente por meio, jornalístico, eles criticavam os governos, a oposição, tanto em nível local como nacional como podemos verificar nas considerações de Camillo:

\begin{abstract}
Por essa época - agosto de 1929 - dois jovens idealistas em Conquista, com a ingenuidade adorável dos românticos e dos entusiastas, acreditaram ser aquela a hora de salvação do Brasil. [...] eles odiavam e repeliam, com justa indignação dos bem intencionados, a posição antidemocrática e antipopular do governo Washington Luiz, não compreendiam o caráter reacionário da Aliança Liberal. [...] Assim Laudionor A. Brasil e Bruno Bacelar de Oliveira de namorados transformaram-se em apaixonados da Aliança, que tão bem, sabia pintarse aos pés da deusa atiraram braçadas de retórica, nuvens de ditirambos, ao tempo em que transformaram as gotas de tinta, com que escreviam, em gotas de veneno contra os senhores da política local e os mandões da política nacional (LIMA, apud, SOUSA; BORBOREMA, 2001, p. 228).
\end{abstract}

A crise político-social da década de 1920, agravada pela expansão da crise econômica de 1929, em todo o Brasil, acabou aglutinando setores da oligarquia com o chamado tenentismo (movimento formado por homens oriundos da classe média que viam na carreira militar um meio de ascender socialmente, tendo como principal líder Luiz Carlos Prestes). Fazendo oposição ao governo de Washington Luiz e seu candidato para as eleições de 1930 o paulista Júlio Prestes e Vital Soares, foi criada Aliança Liberal liderada pelos Partidos: Republicano Mineiro e pela Frente Única Gaúcha, que trouxeram os candidatos oposicionistas Getúlio Vargas e João Pessoa, que cada vez mais ganhavam adesão das maiorias das oposições estaduais inclusive no próprio São Paulo, pretendendo romper de vez com a política do café com leite. Com a vitória de Júlio Prestes, a Aliança Liberal se organizou para promover um levante armado, Vargas convidou Luiz Carlos Prestes que a essa altura já comungava com as ideias comunistas para liderar a Revolução de 1930. Porém em uma união secreta, o primeiro pediu dinheiro e armas para Vargas e lançou a proposta de promover uma revolução popular, o que desagradou o segundo, que mesmo assim lhe emprestou o dinheiro, até maio de 1930, quando Prestes lançou um manifesto radical convocando o povo à insurreição, contrariando as ideias da Aliança Liberal e da maioria dos tenentes que o acompanhavam e romperam com ele em prol de Vargas. Foi mediante uma série de conflitos armados que no final de outubro de 1930, Getúlio Vargas assumiu o poder (VENTURINI, 1997).

Em Vitória da Conquista, assim como no restante do país, acirraram as disputas partidárias. Defendendo a Aliança Liberal que trazia a candidatura de Getúlio Vargas, estavam: Cel. Deraldo Mendes Ferraz, Júlio Guimarães Lacerda, Laudionor de Andrade Brasil, Bruno Bacelar de Oliveira, Manoel Januário de Andrade, Firmino Gusmão, Virgílio Mendes Ferraz, José Vieira Freitas, Antônio Vicente de Andrade, Juvenal Pinheiro de Andrade, os fundadores do Partido Liberal Conquistense. Na oposição estavam os componentes do Partido Republicano Conquistense que defendia Washington Luiz, dentre eles: Otávio José dos Santos Silva, Cassiano Fernandes dos Santos Silva, Zeferino Correia 
de Melo, Luiz Régis Pacheco Pereira. Medeiros (2008) ressalta que, era entre esses grupos que ocorria a disputa pelo poder local, como também prevalecia os fortes laços da parentela, uma especificidade local, porque tanto na oposição quanto na situação estavam presentes membros de uma mesma família que rompiam e formavam outro grupo. São as influências familiares presentes, que ainda permaneciam, nos controles políticos da cidade.

Com a vitória de Vargas, o então intendente Otávio Santos foi afastado do cargo, e assumiu por indicação do Cel. Deraldo Mendes, Bruno Bacelar, que só assumiu durante quinze dias, depois disso ele rompeu com Deraldo por não compartilhar as ideias do mesmo. Assim o interventor baiano Leopoldo Afrânio Bastos do Amaral, indicou Deraldo Mendes para assumir a Intendência Municipal (Prefeitura), e Laudionor Brasil passou a trabalhar na mesma. Em 1931 publicou uma notícia no Combate:

24 DE OUTUBRO: Primeiro aniversário da revolução de 30 [...] o país viveu horas de indescritível entusiasmo ao receber a nova alviçadeira. Somos Livres! É livre o Brasil acabou-se o reinado torpe da mentira eleitoral, das oligarquias nefastas do despotismo, do desrespeito à soberania popular, do mandonismo, do aproveitamento das nulidades bajuladoras e subservientes. Viva o povo, soberano e forte! Salve Terra livre! E das terras ricas dos pampas, onde o minuano passa como o verbo da liberdade, das terras áridas do nordeste, onde o sol arde como um canto de guerra, no Brasil inteiro, houve o delírio das multidões cantando hinos de vibrante entusiasmo aos realizadores do grande feito [...] (BRASIL, O Combate, 1931, Ano III, $\mathrm{n}^{\circ}$ 12).

O governo de Deraldo Mendes vinculado a Juracy Magalhães, foi marcado por um forte clientelismo e não demorou muito para ocorrer uma cisão em seu partido, e Laudionor Brasil, em 1934, se tornar um dos dissidentes conforme salienta Medeiros (in: BRASIL, 2002; 2008).

Assim ele se adentrou ao Partido Autonomista que fazia oposição ao Governador Juracy Magalhães e Deraldo Mendes que tinha como figuras expressivas o médico Dr. Luiz Régis Pacheco Pereira vinculado através do matrimônio à família Santos, uma das famílias mais tradicionais e prestigiadas socialmente e politicamente da cidade. Enquanto Juracy Magalhães permaneceu no poder, a cidade estava com o comando do grupo liderado por Deraldo Mendes, que indicava seus sucessores na prefeitura. O Combate nesse momento passou a fazer oposição ao poder situacionista. Em 1936 Laudionor Brasil foi eleito vereador da cidade pelo Partido Autonomista, onde governou até 1947.

Com as reviravoltas ocorridas no cenário da política a partir da instauração do Estado Novo, houve a queda de Juracy Magalhães, que já não apoiava mais Vargas, e entrou no comando central do governo da Bahia o engenheiro agrônomo Dr. Landulfo Alves, amigo de Régis Pacheco e que por sua vez o indicou para assumir a prefeitura de Vitória da Conquista.

Foi assim que em 1938, foi fundada a Ala de Letras de Conquista, pelos considerados intelectuais da cidade, dentre eles, professores, jornalistas, advogados, no qual estavam dentre outros: Clóvis Lima, Euclydes Dantas, Camillo de Jesus Lima e Laudionor Brasil, que neste ano publicou o livro Vinte anos de amor e de tortura, lançado na Ala de Letras em novembro. Foi muito importante para os letrados da cidade essa Ala, por também proporcionar contato com letrados de outros lugares, dando oportunidade de divulgação das produções e ideias e os manterem atualizados as mudanças da literatura em âmbito regional. Desse modo a produção literária local foi apresentando nova feição e reconhecimento (MEDEIROS. IN: BRASIL, 2002). 
As produções poéticas, nessa cidade em que a política marcava fortemente o cotidiano das pessoas, eram de influência romântica e parnasiana, pouco a pouco foi surgindo à poesia moderna em Conquista, com conteúdo político e social, tendo em Camillo de Jesus Lima e Laudionor Brasil seus principais expoentes.

Camillo de Jesus Lima (LIMA, In: BRASIL, 2002), que ocupava nesse contexto as funções de professor, secretário municipal, redator de $O$ Combate e um dos fundadores da Ala das Letras, se refere ao amigo Laudionor, como companheiro de lutas e de ideais, ainda que eles discordassem de alguns pontos, principalmente na política uma vez que Camillo de Jesus se aproximava cada vez mais do Partido Comunista e de Luiz Carlos Prestes, enquanto que Laudionor permanecia defendendo Vargas. Camillo ainda considerava o amigo também como um romântico, boêmio, sensível às causas dos proletários, por ter sido um deles, como seu pai o foi. De acordo Lima (in: BRASIL, 2002) a própria escolha do nome de um de seus filhos Wladimir, foi em homenagem a um líder revolucionário das causas proletárias. E verificamos em um de seus poemas intitulado slogan um pouco da ambiguidade vivenciada por Laudionor:

\begin{abstract}
Wladimir, meu filho pequenino - olha bem as origens obscuras de onde vieste. Teu avô era um simples operário, humilde e bom. Eu - sou um simples proletário da pena. Nada, portanto, da pretensão de ser um poeta universal. Nada das intenções de ser um grande condutor de homens. Deverás viver no seio do povo, de onde vieste. Modesto, entre os humildes. Bom, entre os pequenos. Mas, se, um dia, passar no teu caminho o vulto de um tirano, não percas, Wladimir, a grande oportunidade: - Dá-lhe a mais firme pedrada que puderes. E terás conquistado para a tua vida um slogan maravilhoso: - Eu apedrejei um tirano (BRASIL, 2002, p. 79).
\end{abstract}

Os ataques antifascistas e a favor dos menos favorecidos, também, aparecem em seus poemas e produções, como: As trevas da noite estão passando, Enquanto a noite envolve o mundo..., Os povos livres ganharão a guerra, se referindo ao caos provocado pela Segunda Grande Guerra e as investidas de Hitler (BRASIL, 2002).

A contradição existente é que apesar de rejeitar o nazismo e utilizar seus versos poéticos contra o mesmo, contra a figura do ditador fascista, Laudionor apoiava Getúlio Vargas, que nas palavras de Camillo de Jesus Lima era quase uma idolatria, como pode ser percebido em seu relato:

o governo brasileiro não ocultava, através da máquina fascista do estado, seus entusiasmos pela causa do mal. [...] parte dessa época uma angústia universal e indignidade oficial brasileira a nova fase poética de Laudionor Brasil. Seus sentimentos de homem livre foram mais forte que a sua predileção inexplicável, quase idolatria, pela pessoa do então chefe do governo, por essa época dileto discípulo e franco colaborador do fascismo (LIMA, in: BRASIL, 2002, p. 31).

Assim prosseguiu Laudionor Brasil, com ideais republicanos de liberdade, fraternidade, igualdade, contrário aos vestígios imperiais, nazifascista e defensor das causas dos menos favorecidos, mesmo porque ele se considerava um deles, como percebemos em alguns de seus poemas tais como ${ }^{7}$ O avarento: "Ah! Ninguém como tu anseia e sofre porque tens a alma na prisão de um cofre, satélite infeliz de moedas de ouro"; Depois, eu farei o teu poema: "Ainda se ouvem nos caminhos do mundo os sons cavos das patas dos ginetes, dos cavaleiros do apocalipse... a besta ainda continua solta", "Quando a estrela estiver no seu zênite, estarão extintas as podridões da terra. E o caboclo da América e o camponês da Ucrânia se estreitarão no mais fraterno abraço"; Мeu Pai: 
"Meu pai era um operário forte e bom [...] para morrer e deixar ao filho, apenas, esta vontade imensa de trabalhar e esta aversão insensível aos exploradores do trabalho alheio"; O poeta canta a sua terra: "vou cantar a minha terra. Nos meus versos, entretanto, não a tornarei rainha porque sou republicano"; $O$ coro triste da sinfonia maravilhosa: "Brasil amado! Porque deixas que o mundo escuta o coro triste da sinfonia maravilhosa do teu progresso, esse lamento na voz de angústia dos teus filhos flagelados?"; Enquanto a noite envolve o mundo: "Ah mas, não será eterna a vossa dor! Breve, os povos livres ganharão a guerra, e, cantando o hino ardente da liberdade, além de erguerem estátuas a Churchill - o vencedor do monstro"

A educação também era um tema de grande interesse para Laudionor Brasil, que acreditava ser a única capaz de promover a república ideal defendida pelo mesmo. É importante ressaltar que nesses tempos, ela passou a ter uma presença cada vez mais forte na vida política, por consequência, se tornou a arena principal em que os combates ideológicos se dariam, devido à crença, quase por todos compartilhados, em seu poder de moldar a sociedade a partir da formação das mentes e abertura de novos espaços de mobilidade social e participação. (SCHWARTZMAN; BOMENY \& COSTA, 1984, p.51).

Os debates, de um lado formados pelo movimento da Escola Nova e do outro pela renovação católica que queria manter seu lugar no novo regime, compuseram o universo político da década de 1930. Nesse ínterim, o discurso de criação de escolas a fim de erradicar o analfabetismo foi motivo de intensas campanhas jornalísticas. Era preciso formar cidadãos capazes de atuar com precisão no cenário produtivo da nação. Então, não bastava apenas garantir escolas às camadas populares e às elites, era preciso discutir os níveis de ensino para cada grupo, um atenderia os interesses da formação da elite e outro atenderia à formação da força de trabalho das camadas populares (CURY, 1984).

Foi assim que através das incursões em alguns exemplares do Jornal $O$ Combate, verificamos que essas ideias, também estiveram presentes no âmbito local, principalmente nos assuntos referentes à educação e progresso através da bandeira em prol da instrução. Como por exemplo:

PELA INSTRUÇÃO: Na Bahia, a instrução pública é deficientíssima, constituindo, por isso mesmo, uma das causas principais da desvantajosa posição que o nosso estado ocupa em relação a S. Paulo, Minas e outros Estados. Apesar disto, verificamos há pouco tempo este lamentável fato: O Governo acaba de reduzir à $177 \$ 332$ os vencimentos mensais dos professores interinos, vencimentos que eram de $266 \$ 000$, quantia já muito reduzida. Uma miséria! Que pode fazer no desempenho do seu árduo e nobre mister um professor que percebe, mensalmente, apenas $177 \$ 000$ ! Como pode um homem, especialmente se é casado, dedicar-se com devotamento, com interesse contínuo, se, por seu esforço, por suas enormes energias gastas, ele há de receber, unicamente em cada de mês, a miséria de $170 \$ 000$ ? Não! Essa é uma medida absurda que se tornou, mas que há de ser transitória, que o deve ser, para que não diga aos outros Estados que o governo da Bahia tudo faz para conservar o povo no mais clamoroso analfabetismo (BRASIL, O Combate, 1930, Ano I, n 39).

Defendendo a instrução baseada em uma pedagogia moderna:

COLÉGIO MARCELINO MENDES: Cuidar bem da educação moral e intelectual de seus filhos é sem dúvida, dever sagrado de quem preza de ser bom pai de família. A instrução está em primeira linha no engrandecimento da pátria e afere-se o conceito de qualquer localidade, não pelos seus edifícios e por suas fortunas públicas e particulares e sim pelo número de estabelecimentos de ensino ali existentes, da organização, 
frequiência e aproveitamento destas instituições. O colégio Marcelino Mendes é um padrão magnífico de cultura física, moral e intelectual, notando o visitante, a primeira vista, mesmo de surpresa, uma organização perfeita, de acordo com os moldes da pedagogia moderna [...] (BRASIL, O Combate, 1932, Ano III, $\mathrm{n}^{\circ} 35$ ).

Notícias enfocando a educação estiveram presentes em outras manchetes e artigos desse jornal, durante as décadas de 1930 e 1940, como podemos verificar abaixo:

A EVOLUÇÃO PEDAGÓGICA NO BRASIL: Artigo feito pelo professor Mario Padre que faz uma contextualização histórica e evolutiva da educação no Brasil, falando dos jesuítas (no ensino primário) e a indiferença de Portugal em relação à instrução nesses primórdios, segundo ele com a vinda de Dom João VI e a corte portuguesa a educação primária teve algum impulso, algumas escolas foram criadas somente para meninos. Foi com D. Pedro I em 1826 que escolas de primeiras letras foram criadas em algumas cidades, vilas e arraiais do país, representando assim certo avanço, pois já demonstrava de acordo com o autor, preocupação oficial do governo. Os métodos de ensino eram péssimos, o mestre mantinha a autoridade através do terror, tendo a palmatória como companheira, o aluno tremia ao ser apresentado ao seu professor e com verdadeiros martírios para a memória com a decoração de nomes e datas sem importância, essa escola terror que afugentava crianças atravessou o Segundo Reinado e a República, porém a partir desta, uma revolução pedagógica ocorreu no Brasil, combatendo a escola antiga (escola régia), através da adoção de novos métodos de ensino como os de: Pestallozzi (pai da pedagogia moderna), Frabel (o inventor do jardim de infância) e Montessori (educadora que abalou o mundo pedagógico). Essa nova escola primária despertou em São Paulo com Lourenço Filho e Sid Menuci, no Rio de Janeiro com Fernando Azevedo, na Bahia com Anísio Teixeira, em Pernambuco com Aníbal Bruno, etc. Cada vez mais ganhando terreno, com materiais didáticos modernos, construindo prédios e sendo preocupação dominante dos dirigentes. Essa escola nova, para Padre, caminha para um futuro feliz na sua Escola Primária Base de todo o progresso (DANTAS, BRASIL. O Combate, 1935, Ano VII, nº1).

PROFESSOR FASCISTA, FORA! - O Professor Integralista Herbert Parentes Fontes Fortes foi afastado do Ginásio da Bahia por desonrar este colégio com seus ensinamentos, indo então para o Rio onde foi nomeado técnico de educação, porém os estudantes expuseram ao ministro Gustavo Capanema quem na verdade ele era e este vetou a nomeação. O jornal louva esta atitude (LIMA, BRASIL. Combate, 1943, Ano XIV, nº 18).

Geralmente os temas abordados no Combate, cotejados até o ano de 1948, abarcavam escolas fundadas, homenagens a professores, referência ao ensino religioso, de corte-costura e datilografia, a questão política (com os professores Integralistas e comunistas), a cruzada contra o analfabetismo e a alfabetização de adultos, a defesa da pedagogia moderna em detrimento do ensino tradicional, considerado arcaico, o que confirma então neste período, a valorização da educação e preocupação em desenvolvê-la em âmbito local. Desse modo verificamos a forma de como a educação estava sendo pensada em Vitória da Conquista através de sujeitos como Laudionor Brasil, que interpretava as discussões nacionais e incorporava junto aos anseios locais. 


\section{Considerações Finais}

Laudionor Brasil foi certamente, um dos nomes que pensaram a educação no processo de implantação dos ideais republicanos na cidade, sua atuação em diversos espaços, sejam eles, na sala de aula, na imprensa, nas agremiações literárias, na política, possibilitou que ocupasse lugares sociais de referência e ascendesse socialmente. Cabe ressaltar que ele era oriundo de uma família menos abastada, e que só teve acesso ao primário incompleto, mas que desenvolveu um autodidatismo, que o incluía no perfil de uma sociedade em transformação. Assim como outros professores contemporâneos seus.

Casado com dona Áurea Celina Brasil, em 1933 e tendo ao longo dos anos nove filhos, Laudionor Brasil a partir da década de 1940, passou a ser reconhecido, fora da cidade, pelas suas atuações, sobretudo literárias, recebendo várias homenagens como a do I Congresso Brasileiro de Escritores em 1945. Mesmo após o término de seu mandato como vereador em 1947, continuou, participando e se interessando pelos assuntos políticos da cidade, como em 1948, quando tornou pública sua adesão a Campanha do Petróleo é Nosso, escrevendo um manifesto a favor do mesmo e continuando a dedicar notícias em seu jornal, que era um dos mais prestigiados e lidos de Vitória da Conquista. A bandeira dentro de assuntos referentes à educação que ele levantava nesse período, juntamente com Camillo de Jesus Lima, era pela Alfabetização de Adultos, ainda considerando a educação como propulsora do progresso da nação e que os males decorriam apenas da ignorância do povo:

ENSINO SUPLETIVO - No Brasil só há um problema nacional: a educação do povo! É este um conceito profundamente verdadeiro, emitido pelo eminente médico brasileiro o Dr. Miguel Couto numa conferência realizada na Associação Brasileira de Educação em 1928. Decorridos mais de vinte anos continua de pé o mesmo problema, como o único cuja solução deve estar a base de todos os demais. Pergunta Miguel Couto: Como nos salvaremos nós? Com a altura do povo, porque da cultura nasce a ambição, da ambição a atividade, da atividade a riqueza, da riqueza multiplicada a fortuna coletiva e desta a confiança, a força, a durabilidade, a coesão. E conclui: O progresso de um país está na razão direta de cultura do povo. É com este pensamento que o Governo Federal fundou milhares de escolas para a alfabetização de adultos e adolescentes abertas em todo o país àqueles que, pelo esforço em prol da sua própria educação, quiserem cooperar para o progresso de nossa pátria (BRASIL, O Combate, 1948, Ano XVIII, nº 24).

Laudionor Brasil faleceu no dia 14 de março de 1950 de problemas cardíacos, e durante os anos que seguiram recebeu várias homenagens, como a de 1960 quando em uma solenidade em prol dos dez anos de seu falecimento, um busto de bronze seu foi colocado na Escola Normal (Instituto de Educação Euclydes Dantas), para que sempre fosse lembrado como o grande intelectual que foi.

O Combate, que continuou até 1964, com seus familiares, em 1960 sob a direção de Solange Brasil (uma de suas filhas), publicou várias notícias homenageando tanto a figura de Laudionor, quanto a do seu Jornal $O$ Combate que completava 30 anos de existência, que apesar de manter relações estreitas com o poder local se intitulava independente e noticioso, enfatizando a importância que estes tiveram na cidade, bem como a necessidade de que ficasse registrada na memória local essa importância. Desse modo no dia 27 de agosto do referido ano, foi noticiada na página principal a homenagem prestada na Escola Normal, quando foi colocado seu busto, tendo como orador oficial Camillo de Jesus Lima (que também foi um dos incentivadores dessa solenidade) e o professor, neste momento 
vereador Everardo Públio de Castro representando a Câmara de Vereadores. No discurso de Camillo de Jesus que foi transcrito no jornal ele destacou e enalteceu as virtudes morais do mesmo que pode ser percebida em alguns de seus trechos:

\begin{abstract}
Envaido-me de ter sido seu redator, por alguns anos, durante os quais nunca ouvi de Laudionor qualquer censura aos meus artigos de doutrinação política, ou aos meus sonetos de combate franco ao fascismo. Se as vezes, levantava restrição ao meu linguajar violento da época, nunca usou dos direitos de diretor para restringir a liberdade de meu pensamento [...] o culto do passado, o amor quase carnal a sua terra, o orgulho da raça, a aversão a prepotência, a coragem na aquisição dos seus ideais e a crença no poder construtivo do amor foram os traços característicos de Laudionor Brasil - o homem e o intelectual [...] (LIMA, in: O Combate, 1960)
\end{abstract}

A Ditadura Civil-Militar de 1964 elegeu os seus próprios heróis, e buscou eliminar quaisquer imagens que considerassem ameaça ao seu governo, assim dentre outras coisas, desapareceu com o busto de Laudionor Brasil, fechou o Jornal $O$ Combate e tentou relegar ao esquecimento a atuação de algumas pessoas na cidade, que eram politicamente ativas, e que ocupavam uma posição de destaque social, como foi o caso dele.

\title{
Referências
}

BRASIL, Laudionor de Andrade. A luz desce da estrela. Vitória da Conquista: Brasil Artes Gráficas, 2002.

CARONE, Edgar. A república velha I. Instituições e classes sociais. Rio de Janeiro/São Paulo: Difel, 1978.

CARVALHO, José Murilo de. A formação das almas: o imaginário da república no Brasil. São Paulo: companhia das letras, 1998.

CURY, Carlos R. Jamil. Ideologia e Educação Brasileira. 2 ed. São Paulo: Cortez, 1984. Autores Associados (coleção educação).

HOLANDA, Sérgio Buarque de. Raízes do Brasil. 26 ed. São Paulo: Companhia das letras, 2007.

LEONARDI, Victor; HARDMAN, Foot. História da Indústria no Brasil. São Paulo: Ática, 1991.

MARAM, Sheldon Leslie. Anarquistas, imigrantes e o movimento operário brasileiro (1890-1920). Rio de Janeiro: Paz e Terra, 1979.

MEDEIROS, Ruy. Conquista: Poder e Conflito nos anos 30 do Século XX. Vitória da Conquista: Blog do Nunes, 2008. Disponível em:

$<$ http://www.blogdopaulonunes.com/noticias_especificas2008a/20080202_noticia_01.htm $>$. Acesso no dia 15/04/09.

OLIVEIRA, Francisco. A emergência do modo de produção de mercadorias: uma interpretação teórica da economia da República Velha no Brasil. In: FAUSTO, Bóris 
(Org). O Brasil Republicano: 1- Estrutura de poder e economia (1889-1930). Tomo III, Vol 1. São Paulo: Difel, 1975.

OLIVEIRA, Jeremias Macário de. A imprensa e o coronelismo no sertão do sudoeste. Vitória da Conquista: editado pelo autor, 2005.

SCHWARTZMAN, Simon; BOMENY, Helena Maria B; COSTA, Vanda Maria Ribeiro. Tempos de Capanema. Rio de Janeiro: paz e terra; São Paulo: USP, 1984. (Coleção estudos brasileiros).

SILVA, Paulo Santos. Âncoras de tradição. Luta política, intelectuais e construção do discurso histórico na Bahia (1930-1949). Salvador: EDUFBA, 2000.

SOUSA, Maria Aparecida Silva de; BORBOREMA, Carlos Gomes. Literatura e política: a trajetória de um poeta militante no interior da Bahia (1930-1975). In: Revista Politéia: história e sociedade. Vitória da Conquista: [s.n], v.1 n.1, p. 225-246, 2001.

VENTURINI, Toni. O Velho: a história de Luiz Carlos Prestes. Documentário que conta a história de Luiz Carlos Prestes. Rio de Janeiro/São Paulo: INFRAERO; Olhar imaginário; Versátil Home Vídeo; Riofilme, 1997.

VIANA, Aníbal Lopes. Revista histórica de Vitória da Conquista. Vitória da Conquista. Edições do autor. Brasil Artes Gráficas LTDA. vol. I, 1982 e v.2, s/d.

\section{Fontes jornalísticas}

EXTERNATO Brasil: aos pais de família. In: BRASIL, Laudionor. Jornal O Combate. Vitória da Conquista. Ano I, nº 26, 22 de fevereiro de 1930.

PELA INSTRUÇÃO. In: BRASIL, Laudionor. Jornal O Combate. Vitória da Conquista. Ano I, no 39, 15 de junho de 1930.

24 DE OUTUBRO. In: BRASIL, Laudionor. Jornal O Combate. Vitória da Conquista. Ano III, nº 12, 24 de outubro de 1931.

COLÉGIO Marcelino Mendes. In: BRASIL, Laudionor. Jornal O Combate. Vitória da Conquista. Ano III, nº 27, 20 de fevereiro de 1932.

EDUCANDÁRIO sertanejo. In: BRASIL, Laudionor; DANTAS, Flaviano. Jornal O Combate. Vitória da Conquista. Ano IV, nº 14, 2 de dezembro de 1934.

A EVOLUÇÃO Pedagógica no Brasil. In: BRASIL, Laudionor; DANTAS, Flaviano. Jornal O Combate. Vitória da Conquista. Ano VII, nº 1, 11 de agosto de 1935.

PROFESSOR fascista fora!. In: BRASIL, Laudionor; LIMA, Camillo de Jesus. Jornal O Combate. Vitória da Conquista. Ano XIV, nº 18, 28 de fevereiro de 1943.

ENSINO Supletivo. In: BRASIL, Laudionor. Jornal O Combate. Vitória da Conquista. Ano XVIII, n² 24, 14 de julho de 1948. 
HOMENAGEM a Laudionor Brasil. In: LIMA, Camillo de Jesus. Jornal O Combate. Vitória da Conquista, 27/08/1960. Ano XXXII, nº 37.

Recebido em outubro-12

Aprovado em maio-13

\section{Notas}

* Título de um ensaio dedicado a Laudionor A. Brasil, publicado no Jornal O combate de agosto de 1946, escrito por Camillo de Jesus Lima. Esse texto é oriundo da pesquisa desenvolvida na dissertação de mestrado intitulada: Memória de Professores Intelectuais como interlocutores do republicanismo em Vitória da Conquista-BA entre os anos de 1910 a 1945, sob a orientação da Profa. Dra. Lívia Diana Rocha Magalhães.

** Doutoranda em Educação pela Universidade Estadual de Campinas - UNICAMP, Bolsista da Capes. Mestre em Memória: Linguagem e Sociedade pela Universidade Estadual do Sudoeste da Bahia - UESB. Membro dos grupos de pesquisa: HISTEDBR - Grupo de Estudos e Pesquisas e Museu Pedagógico: Memória Geracional, Política Educacional e Trajetórias Sociais, danyopera@yahoo.com.br

*** Doutora em Educação pela UNICAMP com Pós-Doutorado em Psicologia Social pela UERJ e estágio na Universidad Complutense de Madri (UCM), Professora Plena da Universidade Estadual do Sudoeste da Bahia, Coordenadora Geral do Museu Pedagógico da UESB e Coordenadora do Programa de Pós-Graduação Stricto Sensu em Memória: Linguagem e Sociedade - UESB. lrochamagalhaes@ gmail.com

${ }^{1}$ Característica destacada por Camillo de Jesus Lima tanto na biografia que fez no livro de Laudionor Brasil (2002), quanto na homenagem que prestou ao mesmo no jornal o Combate de 1960, por seu amigo usar sempre uma gravata de borboleta que ele considerava chamativa.

${ }^{2}$ Livro de poemas lançado em 1938, por Laudionor Brasil, tendo o prefácio de Camillo de Jesus Lima.

${ }^{3}$ Os dados biográficos podem ser encontrados em obras como: BRASIL (2002), com as biografias de Camillo de Jesus Lima e Ruy Medeiros, VIANA (1982), homenagem prestada a Laudionor pelo Jornal O Combate de 1960.

${ }^{4}$ EDUCANDÁRIO sertanejo. In: ANDRADE Laudionor; DANTAS, Flaviano. Jornal O Combate. Vitória da Conquista. Ano IV, n 14, 2 de dezembro de 1934.

${ }^{5}$ EXTERNATO Brasil: aos pais de família. In: ANDRADE Laudionor. Jornal O Combate. Vitória da Conquista. Ano I, nº 26, 22 de fevereiro de 1930.

${ }^{6}$ De acordo Oliveira (2005), O jornal $O$ Combate foi fundado no dia 11 de agosto de 1929 por Laudionor Brasil, e durante os anos que sobreviveu até 1964, teve como redatores os professores Flaviano Dantas, Euclydes Dantas, Clóvis Lima, Camillo de Jesus Lima, Padre Palmeira, Aníbal Viana, e também intelectuais como Erathóstenes Menezes, Orlando Leite e Newton Gonçalves.

${ }^{7}$ Todos esses poemas citados estão publicados em Brasil (2002). 